\title{
Article \\ Effect of Deformation on the Microstructure of Cold-Rolled TA2 Alloy after Low-Temperature Nitriding
}

\author{
Guotan Liu ${ }^{1}$, Huanzheng Sun ${ }^{2}$, Enhong Wang ${ }^{1}$, Keqiang Sun ${ }^{1}$, Xiaoshuo Zhu ${ }^{3}$ and Yudong Fu ${ }^{1, * \mathbb{D}}$ \\ 1 School of Materials Science and Chemical Engineering, Harbin Engineering University, Harbin 150001, China; \\ liuguotan097@163.com (G.L.); WangEH_2021@163.com (E.W.); skq000163@163.com (K.S.) \\ 2 School of Materials Science and Technology, Chongqing University, Chongqing 400044, China; \\ 20190901273@cqu.edu.cn \\ 3 School of Mechanical Engineering, Xinjiang University, Urumqi 830045, China; Zhu-xiaoshuo@hrbeu.edu.cn \\ * Correspondence: fuyudong@hrbeu.edu.cn
}

check for updates

Citation: Liu, G.; Sun, H.; Wang, E.; Sun, K.; Zhu, X.; Fu, Y. Effect of Deformation on the Microstructure of Cold-Rolled TA2 Alloy after Low-Temperature Nitriding. Coatings 2021, 11, 1011. https://doi.org/ 10.3390/coatings11081011

Academic Editor: Michał Kulka

Received: 7 July 2021

Accepted: 19 August 2021

Published: 23 August 2021

Publisher's Note: MDPI stays neutral with regard to jurisdictional claims in published maps and institutional affiliations.

Copyright: (c) 2021 by the authors. Licensee MDPI, Basel, Switzerland. This article is an open access article distributed under the terms and conditions of the Creative Commons Attribution (CC BY) license (https:// creativecommons.org/licenses/by/ $4.0 /)$.

\begin{abstract}
In order to improve the low hardness and poor wear resistance of TA2, this paper proposes a composite process of cold-rolling and low-temperature plasma nitriding with recrystallization. This composite modification process can effectively achieve the dual goals of modifying the matrix structure and surface of TA2 alloy simultaneously. The cold-rolling experimental results indicate that when the deformation rate increases, the small-sized grains in the sample increase significantly, and the grain orientation changes from TD (transverse direction) to RD (rolling direction) and then to TD. The nitriding experimental results indicate that the $\{0001\}$ basal surface texture deflected from the TD direction to the RD direction, $\{10-10\}$ cylindrical texture components gradually increased, and the special orientation phenomenon of cylindrical and conical texture disappeared, it can be seen that an increase in the deformation rate promotes recrystallization. The XRD test results indicate that after low-temperature nitriding, metastable nitriding phase TiN0.26 is formed on the surface of TA2. The SEM morphology of the cross-section shows that a relatively special nitrided zone is formed, and mechanical performance test results indicate the wear resistance and hardness of the alloy increased.
\end{abstract}

Keywords: TA2 alloy; cold-rolling deformation; recrystallization; low-temperature nitriding; microstructure; mechanical properties

\section{Introduction}

Titanium and its alloys have attracted great attention in the fields of scientific research and industrial production due to their outstanding advantages, such as excellent heat resistance, corrosion resistance, biocompatibility, and high specific strength [1-3]. However, the low surface hardness and poor wear resistance of titanium alloys greatly limit its application. The TA2 titanium alloy in this paper belongs to $\alpha$-type titanium alloy [4-6], and this type of alloy cannot be strengthened by a heat treatment process, so in practice, the strength is average in the annealed state [4,7].

Rolling deformation is a commonly used forming technology for TA2 industrial titanium alloy sheets [8,9]. Gurao et al. [10] studied the evolution characteristics of the texture and microstructure of industrial pure titanium alloys under different rolling paths through experiments and self-consistent simulations. S.K. Sahoo et al. [11] studied the texture and microstructure evolution of high-deformation hot-rolled industrial pure titanium under a specific rolling method. The experimental results indicate that the basal surface texture in the alloy sample does not change with the rolling type and the deformation reduction.

After deformation, the hardness increases and plastic toughness decrease for the metal material, which is not conducive to subsequent mechanical processing [11,12]. To facilitate processing, it is usually to anneal and recrystallize the deformed metal to soften the material. With the increase of time and temperature, the annealing recrystallization process is often divided into three stages: recovery, recrystallization, and grain growth [13]. 
Researchers have continued to deepen the research on densely packed hexagonal metals [14-17]. However, there are a few studies on the recrystallization of hexagonal metals, such as titanium. R. J. Contieri et al. [18] studied the recrystallization behavior of cold-rolled titanium plates. Experimental data indicate that the dislocation density of titanium plates increases significantly after cold rolling. When the recrystallization annealing temperature is $650-670{ }^{\circ} \mathrm{C}$, the average recrystallization activation energy is about $156.8 \mathrm{KJ} / \mathrm{mol}$. Hayama et al. [19,20] studied the annealing behavior of cold-rolled titanium alloys and found that $50 \%$ and $70 \%$ deformation rate specimens can be annealed at 700 and $800{ }^{\circ} \mathrm{C}$ for $15 \mathrm{~min}$ to achieve an equiaxed crystalline state.

In recent years, the modification of the mechanical properties of titanium alloys has been a research hotspot in the field of materials. Nitriding is one of the important surface modification technologies for metal materials. Nitriding gives metal materials higher surface hardness and strength without shape and size changes. However, in engineering applications, the nitriding temperature of titanium alloys is usually between 800 and $900{ }^{\circ} \mathrm{C}$. At this temperature, coarse grains, severe high-temperature oxidation, and deep hydrogen diffusion occur. In order to avoid these problems, a lower nitriding temperature is a hopeful solution; therefore, researchers have investigated promoting penetration. $\mathrm{H}$. Kovacl et al. [21,22] studied shot peening as a nitriding promotion process for AISI4140 steel by the comparison experiments of shot peening with different densities. The experimental results indicate that shot peening forms finer crystal grains on the surface of the sample, and the increase of the surface dislocation density accelerates the diffusion of nitrogen atoms. The thickness of the infiltration layer of the sample treated by the shot peening and plasma composite process is almost twice the nitriding treatment alone, and the surface hardness also significantly increases. Liu Rui-Liang et al. $[7,23]$ studied the rare earth infiltration process and found that the surface phase structure of the $17-4 \mathrm{PH}$ martensitic stainless steel after the rare-earth carbonitriding does not change significantly, mainly due to the expansion of martensite containing $\mathrm{C}$ and $\mathrm{N}$ Body $\alpha^{\prime} \mathrm{N}, \gamma^{\prime}-\mathrm{Fe} 4 \mathrm{~N}$, and $\mathrm{CrN}$ are equal in composition. However, after adding rare earth, the structure of the infiltrated layer is denser, and the thickness of the infiltrated layer increases by nearly $50 \%$, also the hardness of the infiltrated layer is increased by about $100 \mathrm{HV}$ and the wear resistance is also significantly improved. In M50NiL steel, the surface hardness increases by 143 HV0.1 because of the addition of rare-earth atoms and the thickness of the nitrocarburized layer increases by $39 \mu \mathrm{m}$. As a pretreatment method to accelerate the nitriding process, coldrolling deformation can theoretically not only refine the substructure of the surface layer of the metal material but also increase the dislocation density inside the metal material and increase the storage distortion energy, thereby reducing the $\mathrm{N}$ diffusion activation energy of the atom infiltration. At present, the research on deformation promotion technology is still in the experimental stage, and the materials are mostly steel. However, the research papers on the deformation promotion of hexagonal close-packed metals are rarely reported.

Based on the research in the past few years [24-26], we figured that low-temperature $\left(\leq 550{ }^{\circ} \mathrm{C}\right)$ plasma-nitriding treatment could be used as the preferred surface modification process for titanium alloy, and cold-rolling deformation can promote plasma nitriding. In this paper, a treatment process of cold-rolling deformation and low-temperature nitriding at $450{ }^{\circ} \mathrm{C}$, causing simultaneous recrystallizations, was designed to perform compound modification treatment on TA2 industrial pure titanium alloy. Under cold deformation conditions, a large number of defects (such as point defects and dislocations) are generated, and the lattice distortion energy stored in the polycrystalline metal continuously increases; these promote the diffusion and migration of $\mathrm{N}$ atoms during the low-temperature ion nitriding process. The temperature of the nitriding was designed within the recrystallization temperature of TA2 to achieve the effect of low-temperature nitriding composite recrystallization. This process can not only realize the control of the alloy matrix structure but also effectively improve the wear resistance of the alloy. In this paper, the evolution of the microstructure after cold rolling, the impact of deformations on the recrystallization, 
the evolution of the recrystallized matrix under different deformations, the surface phase structure, and wear resistance after low-temperature nitriding are investigated.

\section{Materials and Methods}

The TA2 alloy used in this paper belongs to commercial titanium, and its chemical composition (wt $\%$ ) is $0.106 \% \mathrm{Fe}, 0.0155 \% \mathrm{C}, 0.0135 \% \mathrm{~N}, 0.0005 \% \mathrm{H}, 0.1165 \% \mathrm{O}$, and the balance is Ti. The metallographic structure is composed of fully annealed recrystallized phases. Plastic deformation occurs at room temperature, and the sample size is $15 \times 15 \times \mathrm{X} \mathrm{mm}$. The length of the sample is parallel to the rolling direction (RD), and the sample height $X$ is $20 \mathrm{~mm}$ ( $0 \%$ deformation rate), $16 \mathrm{~mm}(20 \%), 12 \mathrm{~mm} \mathrm{(40 \% ),} 8 \mathrm{~mm}(60 \%)$, and $4 \mathrm{~mm}(80 \%)$, respectively. The incoming TA2 samples with a thickness of $20 \mathrm{~mm}$ were rolled several times at room temperature, but the maximum reduction did not exceed $0.2 \mathrm{~mm} / \mathrm{time}$. After cold rolling, the plasma nitriding was performed at $450{ }^{\circ} \mathrm{C}$ for $16 \mathrm{~h}$ in a pulsed plasma furnace with a voltage setting of $650 \mathrm{~V}$, and the atmosphere's ratio of $\mathrm{H} 2$ and N2 is 5:7.

The experimental samples were mechanically polished in order with 400, 800, 1500, and 2000 sandpaper and ultrasonically cleaned and then placed in the furnace. The nitrided samples were polished and ultrasonically cleaned. The samples used for OM $\backslash$ SEM $\backslash$ EBSD have been chemically corroded (corrosive solution $\mathrm{HF}: \mathrm{HNO}_{3}: \mathrm{H}_{2} \mathrm{O}=2: 1: 17$ ) after mechanically polishing. The specimens for EBSD characterization were electro-polished in an electrolyte consisting of $6 \mathrm{~mL}$ perchloric acid, $34 \mathrm{~mL} \mathrm{n}$-butanol, and $60 \mathrm{~mL}$ methanol with a direct current of 1 A for $1 \mathrm{~min}$. An OLYMPUS-PM3 (OLYMPUS, Fukuoka, Japan) metallographic microscope was used to observe the microstructure of the initial and cold-rolled samples. A JEOL JSM-6480A scanning electron microscope (SEM, Thermo Fisher Scientific, JEOL, Tokyo, Japan) equipped with an energy spectrum analyzer (EDS) was used to analyze the micro-area composition. The acceleration voltage of the EDS test was $20 \mathrm{kV}$. An X-Pert Pro XRD analyzer (Rigaku, Japan) was used to study the phase composition of the nitride layer, and a copper target continuous scan mode was used, where the scan rate was $5^{\circ} / \mathrm{min}$ and the range of $2 \theta$ was 20 to $80^{\circ}$. The original microstructure, cold-rolled microstructure, and recrystallized microstructure were measured using TESCAN MAIA3 ultra-high-resolution field emission scanning electron microscope (EBSD) (TESCAN, Brno, Czech Republic), the acceleration voltage of EBSD test was $20 \mathrm{kV}$, scanning step sizes of 1.6 and $0.6 \mu \mathrm{m}$ were adopted for deformed and nitrided samples, respectively. The test data is analyzed with Channel 5 software. By analyzing the data collected in the experiment, the crystal grain size, shape characteristics, grain boundary distribution, and orientation of the crystal can be obtained. The indentation hardness is measured by the HVS-1000 hardness tester (Times Mountain, Beijing, China) with the load setting of $50 \mathrm{~g}$ and a dwell time of $15 \mathrm{~s}$. Five measurements were performed for each test sample, and the values were read 10 times. The abrasion test was carried out by a Pin-On-Disk-1-Auto testing machine (Zhongke Kaihua, Lanzhou, China) with GCr15 grinding ball material. It was set under a load of $5 \mathrm{~N}$, a wear rate of $200 \mathrm{r} / \mathrm{min}$, and a wear time of $20 \mathrm{~min}$.

\section{Results and Discussion}

\subsection{Initial Microstructure of TA2 Alloy}

As shown in Figure 1, the initial microstructure of the TA2 alloy sheet before cold deformation is listed with the magnifications of 200 and 500 times, respectively. The initial material is a fully annealed recrystallized structure, without deformed or twin structures, and the grain size is uniform with an average value of about $22 \mu \mathrm{m}$. 

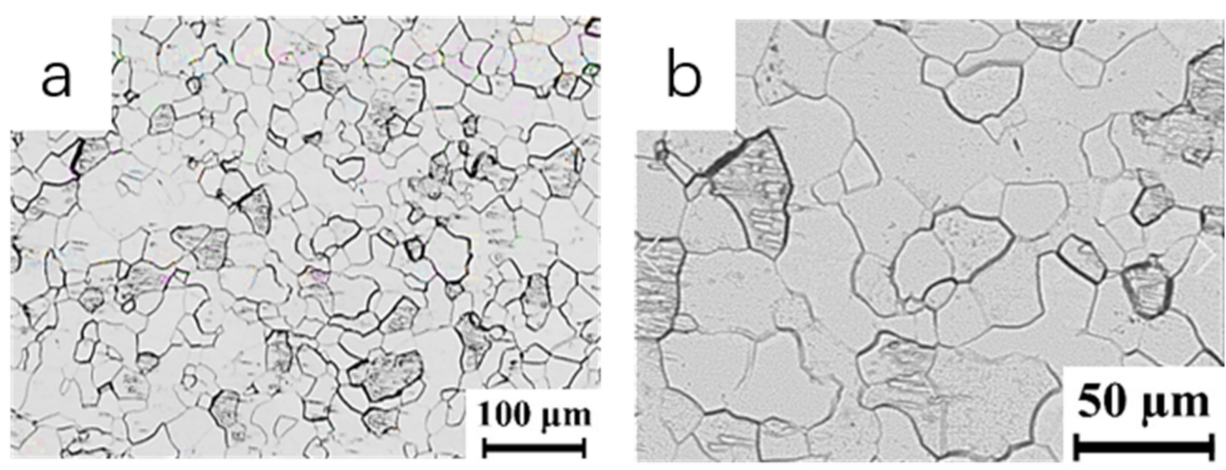

Figure 1. Initial microstructure of TA2 alloy sheet before cold deformation. (a) $200 \times$ (b) $500 \times$.

In Figure 2, the surface shown is the rolling surface, and the horizontal direction is the rolling direction, as well as the vertical direction, is the normal direction of the rolling plane. Figure 2a is the contrast map of the initial state TA2 alloy sheet. The initial structure in Figure 2a belongs to the typical annealed equiaxed structure, and there is no lamellar twin structure. This is consistent with the observation of the microstructure. In Figure 2b, $\{0001\}|| N D$ crystal grains account for a relatively high proportion; the transition color crystal grains account for the largest proportion, indicating that the c-axis of most crystal grains deviates from the ND direction.
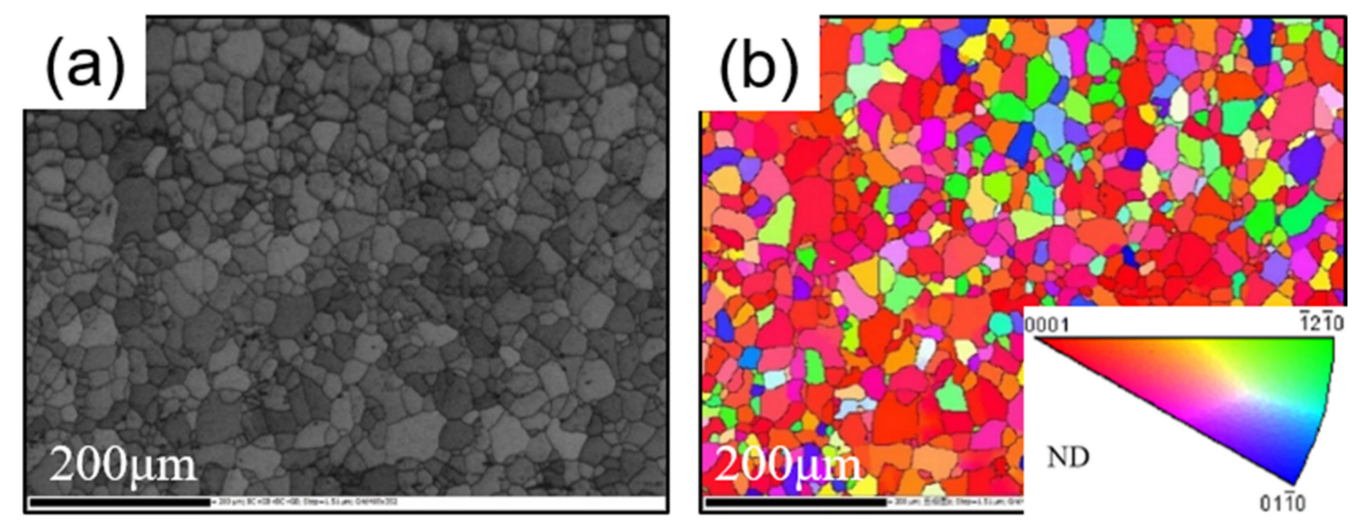

Figure 2. EBSD data of incoming sheet material. (a) contrast map and (b) grain orientation map.

\subsection{Microstructure of Cold-Rolled TA2}

The microstructure of TA2 alloy sheets with different cold-rolling deformation $(20 \%$, $40 \%, 60 \%$, and $80 \%$ ) is shown in Figure 3, and the magnifications are 200 times and 500 times, respectively. Through these, the evolution of the alloy microstructure caused by the degree of deformation is investigated. Compared with the undeformed microstructure in Figure 1, the increase in the deformation rate makes the grains elongated in the rolling direction, and the unevenness of the microstructure is gradually increased. For the $20 \%$ deformed sample, as shown in Figure $3 a, b$, due to its low degree of deformation, there is not much change compared with the initial sample; only a small part of the deformed structure exists, and the grain distribution is relatively even. Among them, the $20 \%$ and $40 \%$ deformed samples have a smaller degree of grain boundary damage, and the percentage of complete grains is higher than that of the bigger deformed samples. When the deformation rate increases to $40 \%$, the deformation degree of the grains increases significantly. When the deformation exceeds $40 \%$, as shown in Figure $3 e-h$, the grain boundaries are severely broken, and almost no complete grains are observed, so the degree of grain fragmentation and refinement increases significantly, when deformation reaches the rolling limit state, as shown in Figure 3g,h, a typical cold-rolled deformation microstructure forms. 

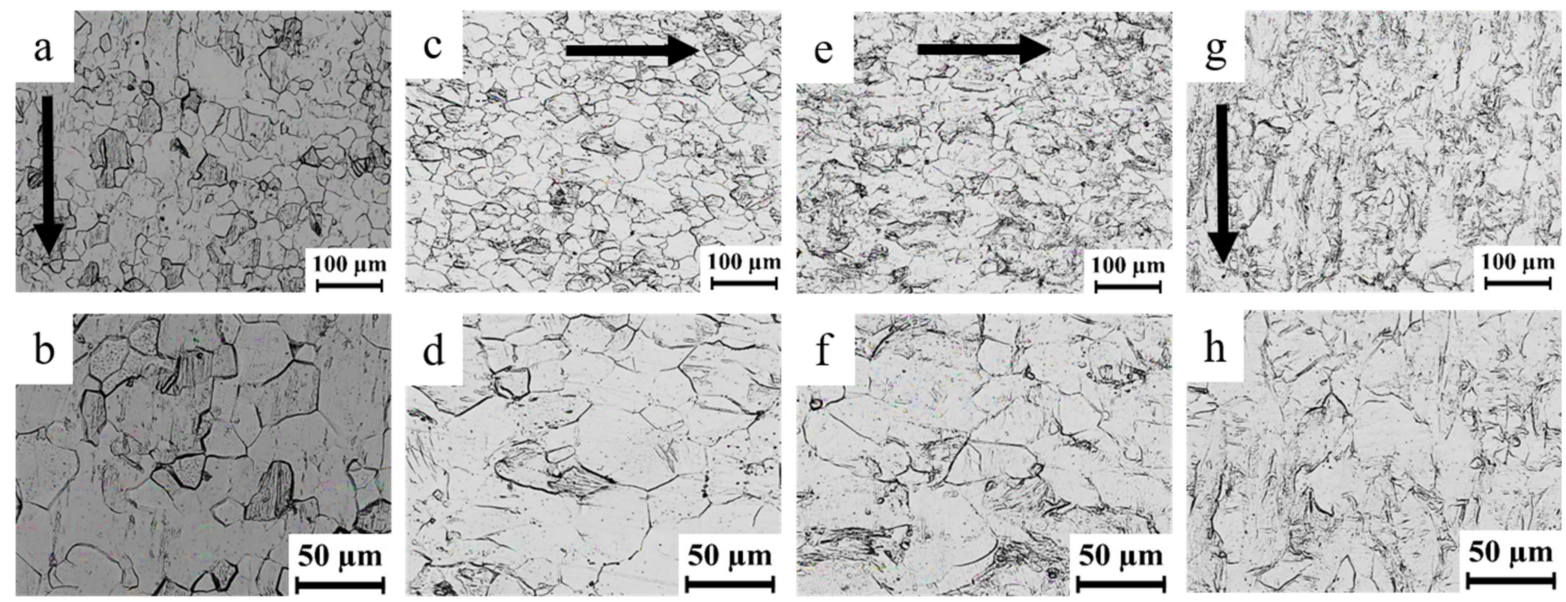

Figure 3. Metallographic structure of TA2 alloy with different deformation: (a,b) $20 \%,(\mathbf{c}, \mathbf{d}) 40 \%$, (e,f) $60 \%$, (g,h) $80 \%$.

The EBSD pole figures of the $0 \%, 40 \%$, and $80 \%$ deformed samples are shown in Figure 4. Basically, the cold-rolled deformed titanium alloy still maintains a typical bimodal distribution. When the deformation reaches $40 \%$, the basal surface texture deflects by $90^{\circ}$ from the TD to the RD direction, resulting in a significant orientation change. In addition, almost no basal texture component forms in the ND direction. When the deformation rate increases to $80 \%$, the texture orientation changes $90^{\circ}$ from $\mathrm{RD}$ to $\mathrm{TD}$, and the concentration of texture distribution is significant.

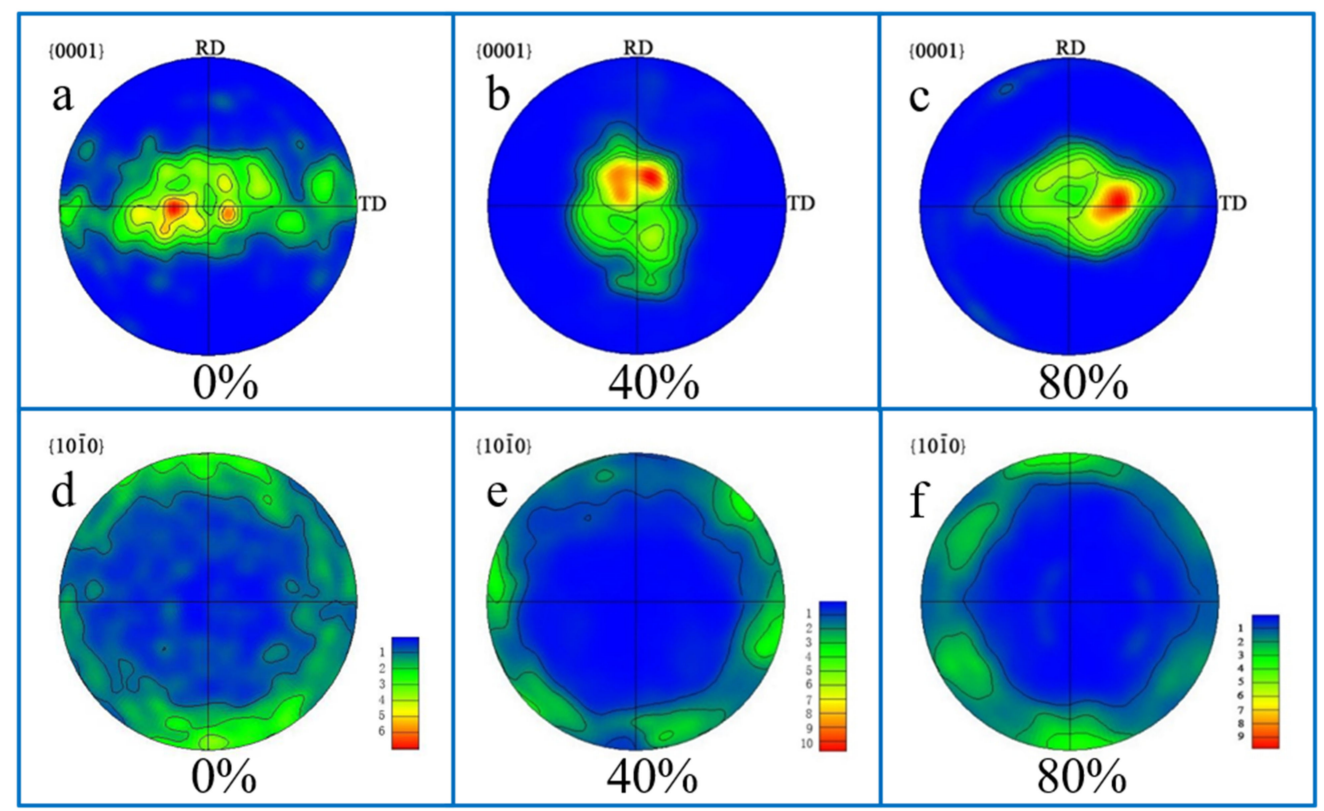

Figure 4. Pole figure of cold-rolled TA2 with different degrees of cold-rolled deformation: (a,d) $0 \%$ deformed, (b,e) $40 \%$ deformed, (c,f) $80 \%$ deformed.

Compared with the $0 \%$ deformed samples, the strength of the cold-deformed texture structure significantly increases, and the texture strengths of the $40 \%$ and $80 \%$ deformed samples are 10 and 9.9 , respectively. In the $\{10-10\}$ pole figure, the intensity of the texture component in the $\{10-10\}|| R D$ direction presents an increasing trend with the increase of the deformation rate. Compared with the undeformed samples, the degree of "stray" of the cylindrical texture and cone texture distribution of the $40 \%$ and $80 \%$ deformed samples significantly reduces, indicating a preferred orientation. 


\subsection{Characterization of Microstructure after Deformation and Nitriding}

Conventional nitriding will cause the crystal grains of the titanium alloy to coarsen and cannot form a good matrix structure $[27,28]$. Next, we studied the microstructure changes of the matrix after cold rolling and low-temperature nitriding. Figure 5 shows the grain orientation map of TA2 alloy with different degrees of cold rolling. Figure 6 shows the grain orientation map and reverse pole map of $40 \%$ and $80 \%$ deformed samples after nitriding treatment $\left(450{ }^{\circ} \mathrm{C} \times 16 \mathrm{~h}\right)$. In Figure $6 \mathrm{a}$, the proportion of grains in the $\{0001\}$ direction (red color) significantly reduces compared to Figure $5 \mathrm{a}$, while the number of green and blue grains slightly increases. In addition, the number of transition color grains (as shown by the blue arrow in Figure 5a) increases significantly. This indicates that grain orientation rotates from the $\{0001\}$ direction to the $\{01-10\}$ direction, which is an obvious recrystallization state but with a low crystallization nucleation rate. In addition to the change in the orientation of grains, the elongation of the grains in the structure is significant, which is consistent with the changes in the grain size in the upper section. Figure $6 \mathrm{~b}$ presents the grain orientation map and the inverse pole map of the $80 \%$ deformed sample after nitriding. The number of complete fine grains in Figure $6 \mathrm{~b}$ significantly increases compared to Figures $5 b$ and $6 a$, and the transition color grains significantly reduce, indicating the alloy structure has a higher degree of recrystallization, and the structure in the blue box is completely equiaxed. In addition, the number of grains in the $\{0001\}$ direction significantly reduces, and the deformed structure and substructures along the arrow direction still exist but are significantly reduced compared to the $40 \%$ nitriding sample.
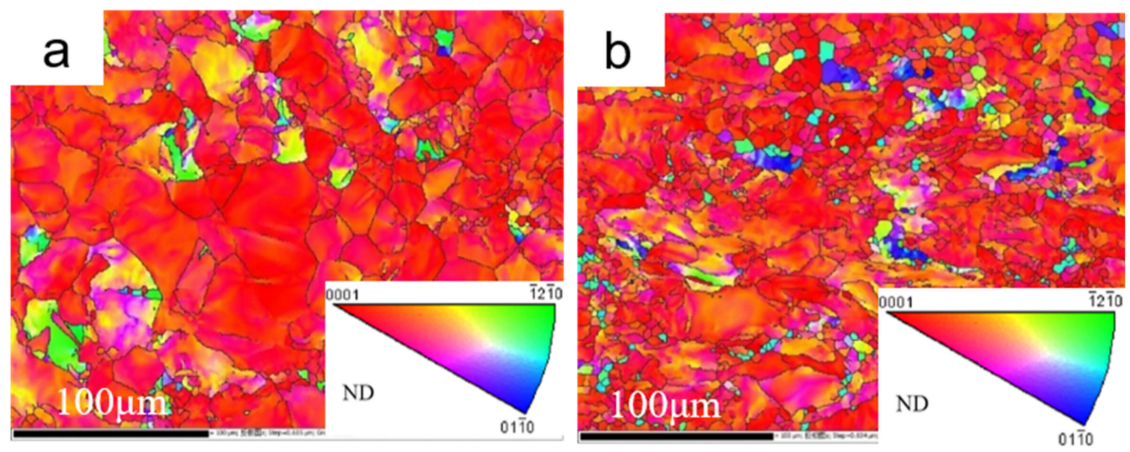

Figure 5. Grain orientation map of TA2 alloy with different degrees of cold-rolling deformation. (a) $40 \%$ and (b) $80 \%$.
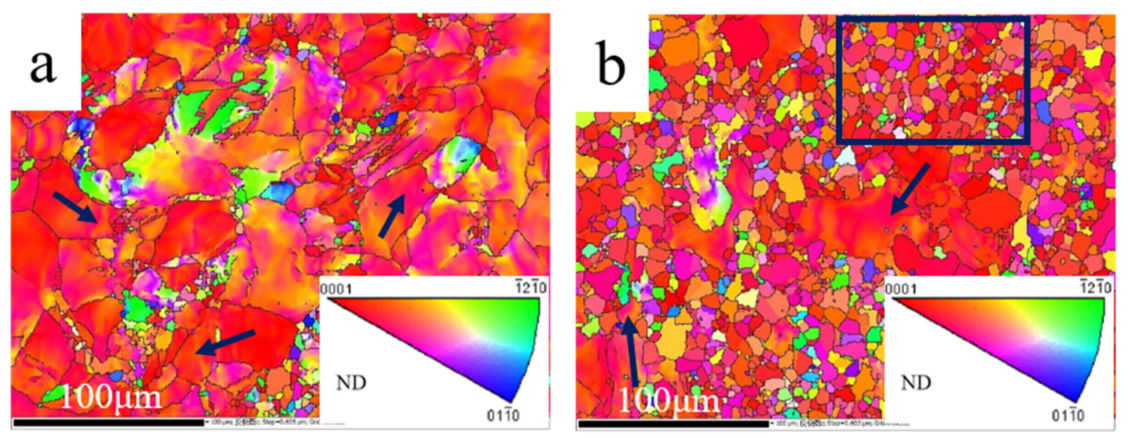

Figure 6. Grain orientation map of cold-rolled deformed TA2 alloy sample after nitriding treatment. (a) $40 \%$ and (b) $80 \%$.

\subsection{The Influence of Nitriding on Texture}

Figure 7 shows the pole figures of cold-rolled deformed TA2 alloy after nitriding. Compared with Figure $4 \mathrm{~b}, \mathrm{c}, \mathrm{e}, \mathrm{f}$, it can be seen that after the $40 \%$ deformed sample undergoes nitriding treatment, the $\{0001\}$ texture parallel to the RD direction has undergone a significant orientation change, from being parallel to the RD direction to being parallel to the TD direction, and the position of the maximum pole density is also approximately 
rotated by $90^{\circ}$. Only a few crystal grains on the TD-ND plane have a c-axis perpendicular to the RD direction, and most of the crystal grains on this plane have a c-axis deviated from the ND direction by $45-90^{\circ},\{10-10\}$ the degree of dispersion of the cylindrical texture in the RD-TD plane increases, and the texture changes along the ND direction are relatively subtle; the basal texture $\{0001\}$ of the $80 \%$ deformed sample after nitriding treatment showed double peaks in the RD-TD plane, but the highest strength of the texture was reduced from 9.87 to 8.55 compared with the cold-rolled state. In addition, the divergence of the cylindrical texture $\{10-10\}$ has increased significantly, and the texture of $\{10-10\} \|$ RD that originally existed at the extreme position of the RD direction is almost nonexistent, and the texture of the special angle orientation is greatly reduced, and the new texture appears at the pole position in the TD direction. Compared with the $40 \%$ deformed sample after nitriding, the $\{10-10\}$ cylindrical texture component in the ND direction gradually increases.

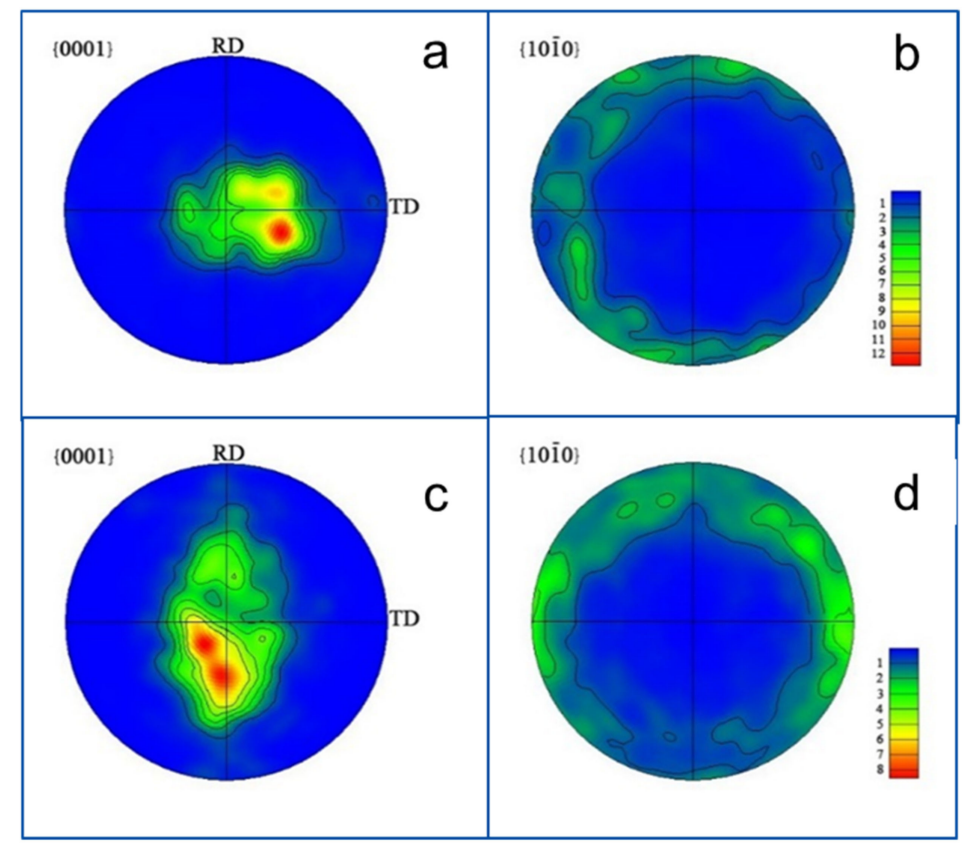

Figure 7. EBSD pole figures of cold-rolled deformed TA2 alloy after nitriding. (a,b) $40 \%$ deformed and (c,d) $80 \%$ deformed.

\subsection{The Phase Composition after Low-Temperature Nitriding}

Figure 8 shows the surface XRD pattern of different deformation rate samples after nitriding at $450{ }^{\circ} \mathrm{C}$ for $16 \mathrm{~h}$. In Figure 8 that the main phases contained in the surface layer of the TA2 sample after nitriding for $16 \mathrm{~h}$ are $\alpha$-Ti and TiN0.26. This is similar to F.S. Braz's research results [29], who also obtained the same compound in the $450{ }^{\circ} \mathrm{C}$ nitridation experiment. Of course, the surface may actually contain steady-state nitride, but it was not detected because of its small content. After nitriding, the metastable titanium nitride compound phase TiN0.26 forms on the surface of the $40 \%, 60 \%$, and $80 \%$ deformed samples. The TiN0.26 phase peak of the $20 \%$ deformed sample is almost as weak as the $0 \%$ deformed sample. The reason is that the small deformation does not produce enough defects inside the sample, resulting in a poor nitriding effect. Different samples of other deformation rates, the $\alpha$-Ti's peak positions of the $40 \%$ deformed sample shift to near 35 and $63^{\circ}$. In the process of low-temperature nitriding of cold-rolled alloy samples, the orientation of the $\{0001\}$ basal plane texture changes, and the c-axis direction of the grains shifts. According to the Bragg equation ( $2 \mathrm{~d} \sin \theta=\mathrm{n} \lambda)$, the change of interplanar spacing (d) will affect the change of " $\theta$ " angle; these are the reasons for the peak position shift. 


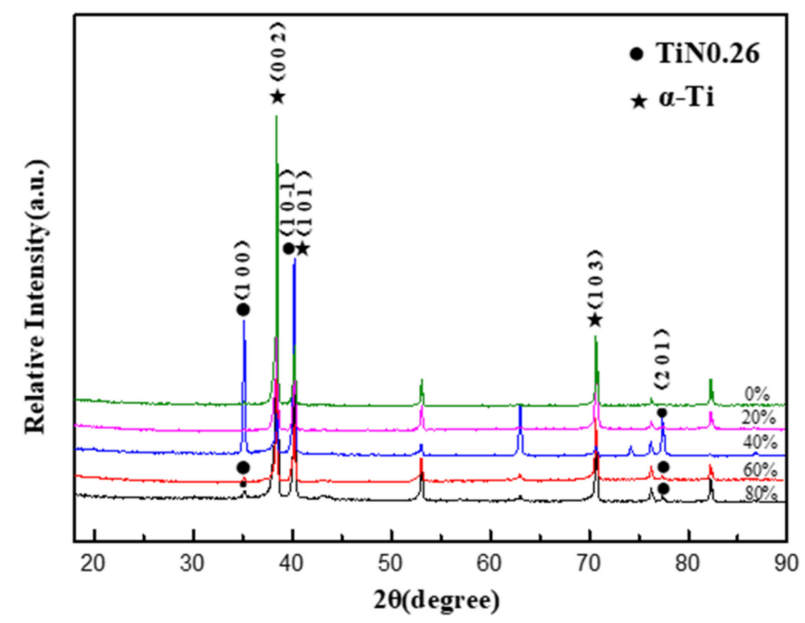

Figure 8. Surface XRD pattern of series of deformed alloy samples after nitriding at $450{ }^{\circ} \mathrm{C}$ for $16 \mathrm{~h}$.

In Figure 9, the EDS point analysis of the chemical composition of the $0 \%, 20 \%, 40 \%$, $60 \%$, and $80 \%$ deformed samples after $450{ }^{\circ} \mathrm{C}$ for $16 \mathrm{~h}$ nitriding treatment are listed. The point scanning positions are marked in each sub-picture, where spherical particulate matter exists. The element content in the scanning area is shown in Table 1. In Table 1, it indicates that with the increase of the deformation rate of TA2 samples, the mass percentage of $\mathrm{N}$ element first increases and then decreases, and the nitrogen-titanium atomic ratio also indicates, at first, an increasing and then decreasing trend. After the deformation rate exceeds $40 \%$, the nitrogen atom content of the white spherical particulate matter decreases because the increase in defect density and the weakening of the interaction force between atoms accelerates the diffusion of active nitrogen atoms, and more $\mathrm{N}$ on the surface diffuses into the inside. The $60 \%$ sample has the highest surface nitrogen atom content of $76.07 \%$, and the nitrogen-titanium atom ratio is about 3:1. In addition, the bigger the size of the white particles selected at special points is, the higher the $\mathrm{N}$ element content is.
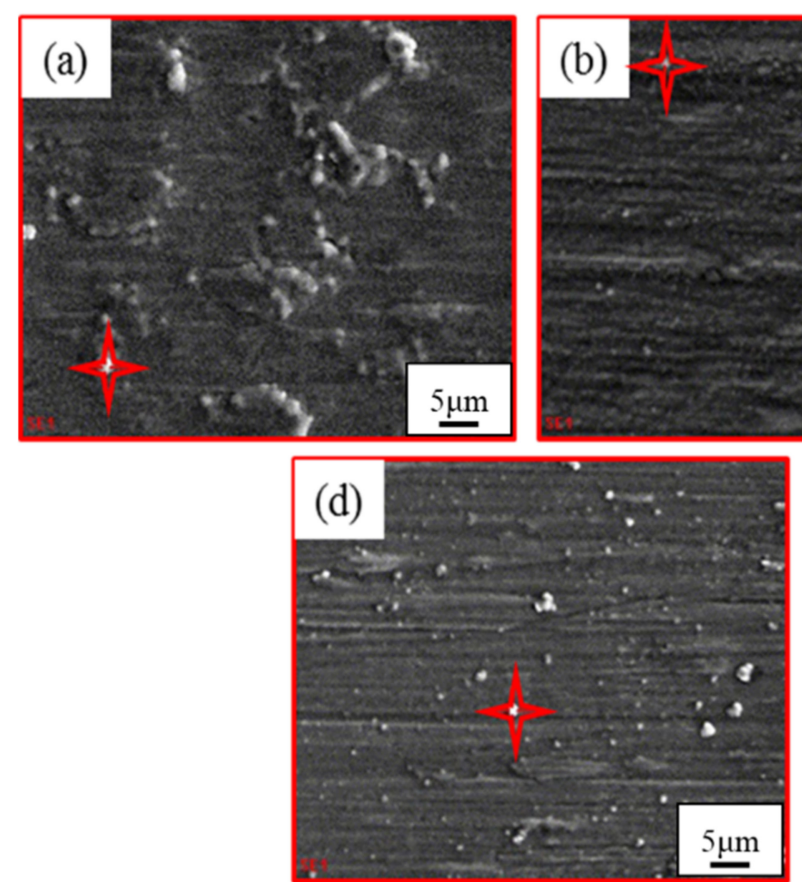
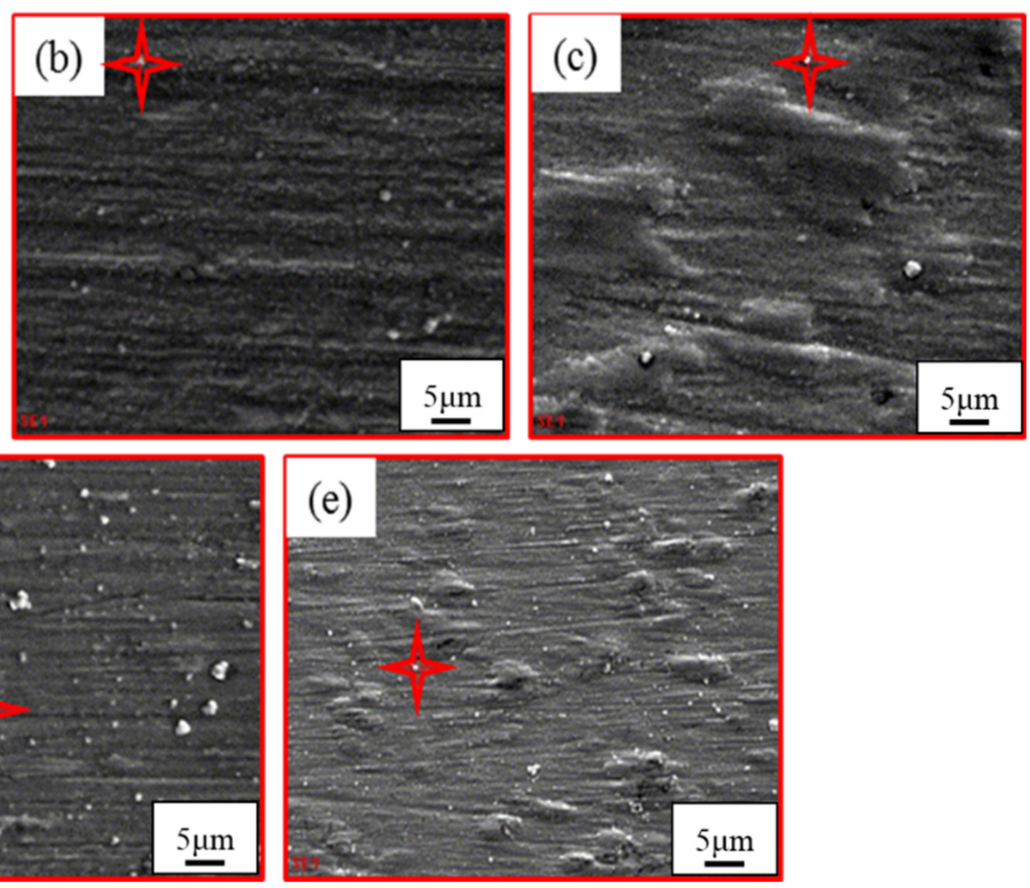

Figure 9. Location selection map of EDS spectrum analysis after TA2 low-temperature nitriding. (a) $0 \%$ deformed, (b) $20 \%$ deformed, (c) $40 \%$ deformed, (d) 60\% deformed, and (e) $80 \%$ deformed. 
Table 1. EDS Energy Spectrum Test Data of Special Points After Nitriding Series of Deformed Alloys.

\begin{tabular}{ccccc}
\hline \multirow{2}{*}{ Deformation } & \multicolumn{2}{c}{ Element (N) } & \multicolumn{2}{c}{ Element (Ti) } \\
& W (t) $\%$ & A (t) $\%$ & W (t) \% & A (t) \% \\
\hline $0 \%$ & 25.8 & 54.3 & 74.3 & 45.8 \\
$20 \%$ & 30.0 & 59.5 & 70.0 & 40.5 \\
$40 \%$ & 29.3 & 58.6 & 70.7 & 41.4 \\
$60 \%$ & 48.2 & 76.0 & 51.8 & 23.9 \\
$80 \%$ & 23.8 & 51.6 & 76.3 & 48.4 \\
\hline
\end{tabular}

\subsection{Morphology of TA2 Alloy Samples under Different Degrees of Cold Deformation}

In the traditional high-temperature nitriding process, a brighter color compound layer will be observed in the cross-sectional morphology of the nitriding sample, and continuous nitrides will be distributed near the surface [30]. This article describes a new nitriding process for the recrystallization of TA2 alloy low-temperature nitriding composite matrix. Under the influence of low-temperature conditions and pre-deformation, a nitriding microstructure different from the traditional nitriding process may appear. Figure 10 shows the SEM morphology of the cross-section of TA2 alloy samples after lowtemperature nitriding; it can be seen from the figure that there is no bright white nitride layer under various deformations. Combining the XRD and EDS data in Section 3.5, it can be inferred that a single metastable nitride phase should only be formed near the surface. In addition, we speculate that a nitriding zone with a gradient distribution of $\mathrm{N}$ elements is formed in the area below the surface because, at lower temperatures, active $\mathrm{N}$ atoms can diffuse into the depth of the matrix through defect channels generated by pre-deformation. Finally, the nitriding microstructure generated by the nitriding process described in this article should be a gradient nitriding region, and there is no obvious nitriding layer, but the $\mathrm{N}$ element is distributed in a gradient from the surface to the core.

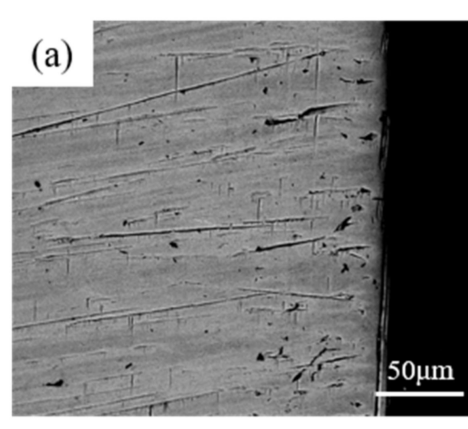

(d)

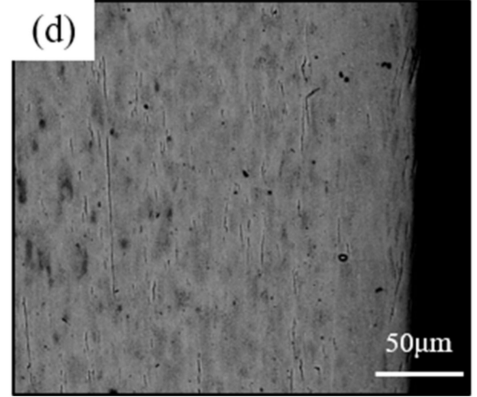

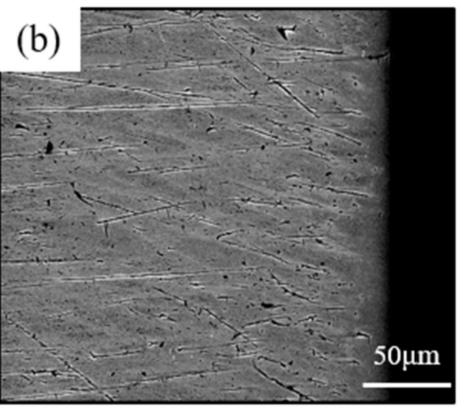
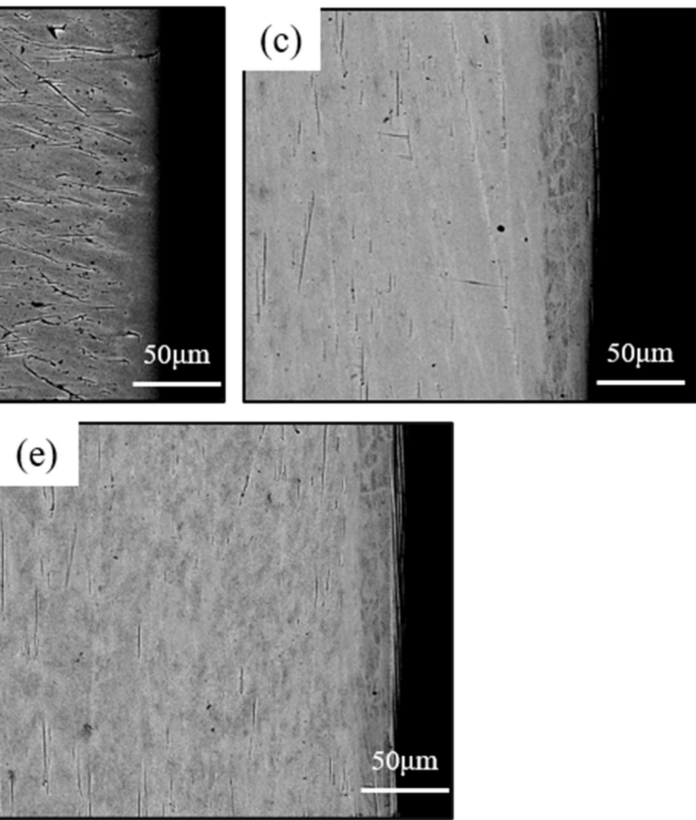

Figure 10. SEM morphology of a cross-section of a TA2 alloy sample after low-temperature nitriding. (a) $0 \%$ deformed, (b) $20 \%$ deformed, (c) $40 \%$ deformed, (d) $60 \%$ deformed, and (e) $80 \%$ deformed.

\subsection{Research on Mechanical Properties after Low-Temperature Nitriding}

Figure 11 shows the friction coefficient curves of alloy samples with different deformation degrees after cold rolling and after nitriding. As Figure 11a shows, after cold rolling, the friction coefficient value of the undeformed sample is stable at about 0.71 , which is the 
maximum value of all the test samples. The minimum coefficient of friction of the deformed sample is 0.48 , which is $31.5 \%$ lower than that of the undeformed sample. Among them, the friction values of the $40 \%$ and $60 \%$ deformed samples are stable at about 0.5 .

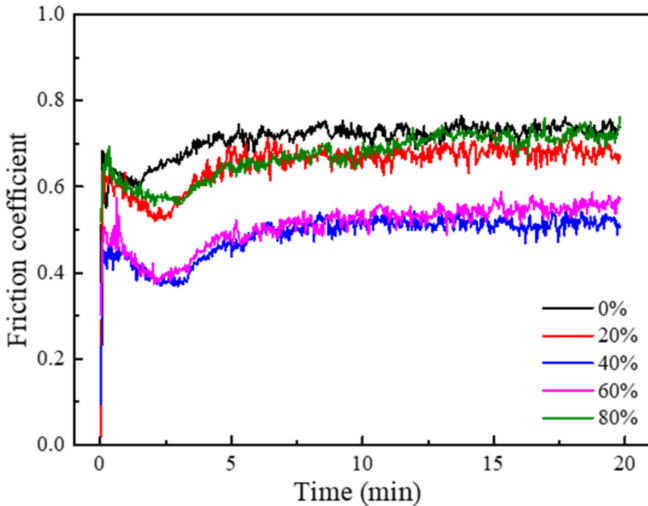

(a)

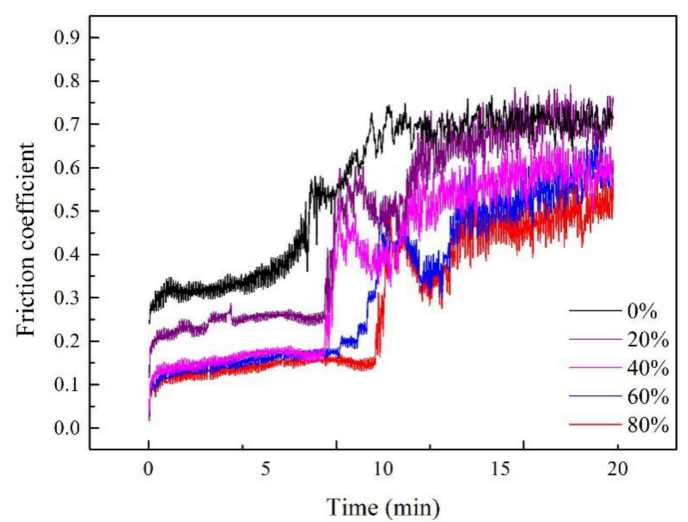

(b)

Figure 11. Friction coefficient curves of alloy samples with different deformation degrees after nitriding. (a) After cold rolling and (b) after nitriding.

As Figure $11 \mathrm{~b}$ shows, after the nitriding process, the stable friction coefficient indicates a decreasing trend with the increase of the deformation rate. The friction coefficient curve changes at $0 \%, 20 \%$, and $40 \%$ deformation are similar. The stable value of the friction coefficient of the $20 \%$ deformed sample has a small difference compared with the $0 \%$ deformed sample, which is stable at about 0.7 ; the stable friction coefficient of the $40 \%$ deformed sample is about 0.53 . The stable friction coefficient of the $60 \%$ deformed sample and the $40 \%$ deformed sample are almost the same; the stable friction coefficient of the $80 \%$ deformed sample is about 0.5 . Both $20 \%$ and $40 \%$ deformed samples have obvious wear stages with low friction coefficients after nitriding treatment, which are stable at about 0.25 and 0.15 , respectively, the duration of this process is about $7 \mathrm{~min}$, while the $0 \%$ deformed samples show a steady state at the same time. There is an upward trend, and there is no declining trend after $7 \mathrm{~min}$. When the deformation rate exceeds $40 \%$, the low friction coefficient wear stage takes longer, and the time required for $80 \%$ deformed samples reaches $10 \mathrm{~min}$, while the friction coefficient values of the $40 \%, 60 \%$, and $80 \%$ of deformed samples at this stage have little difference, stable at about 0.14 . In addition, the friction coefficient of the $20 \%$ deformed sample after $14 \mathrm{~min}$ of the friction test is the same as that of the $0 \%$ deformed sample, which is stable at about 0.7 ; the friction coefficient of the $40 \%$ deformed sample at the same stage is about 0.57 , which is $18.6 \%$ lower than the $0 \%$ deformed sample. The friction coefficient values of the $60 \%$ and $80 \%$ deformed samples still show an increasing trend after $14 \mathrm{~min}$.

The low friction coefficient wear stage fully proves that the infiltration layer formed on the surface of the cold-rolled deformed alloy sample after the low-temperature nitriding treatment can effectively improve the wear resistance of the alloy, and the increase in the amount of cold-rolled deformation promotes the improvement of the wear resistance. Combining the analysis in the previous section, it can be seen that the reason for the short duration of the low friction coefficient wear stage should be that only a single metastable nitride is formed near the surface, and no continuous nitride region is formed below the surface.

Figure 12 shows the microhardness values of cold-rolled deformed alloy samples before and after nitriding. As Figure 11 shows, after $16 \mathrm{~h}$ of nitriding treatment, the microhardness value of TA2 with deformation after low-temperature nitriding treatment is higher than that of the only deformed, of which the $80 \%$ deformed samples' increase is the smallest at only $1.7 \%$; the increase of microhardness of other deformation rate is around $8.3 \%$. Comparing the hardness of different deformation rates after low-temperature 
plasma nitriding treatment, the hardness increases with the increase of the deformation rate. The hardness of the $80 \%$ deformed sample has a small increase. The reason is that the nitriding process is synchronized with the recrystallization treatment and the $80 \%$ deformed structure is more recrystallized, and the plasticity and toughness of the structure are significantly improved, which in turn causes the microhardness to decrease, this partly negates the effect of nitriding. Combined with the XRD results, the reason for the less increase in surface hardness after nitriding is also due to the formation of metastable nitrides with a lower hardness on the surface.

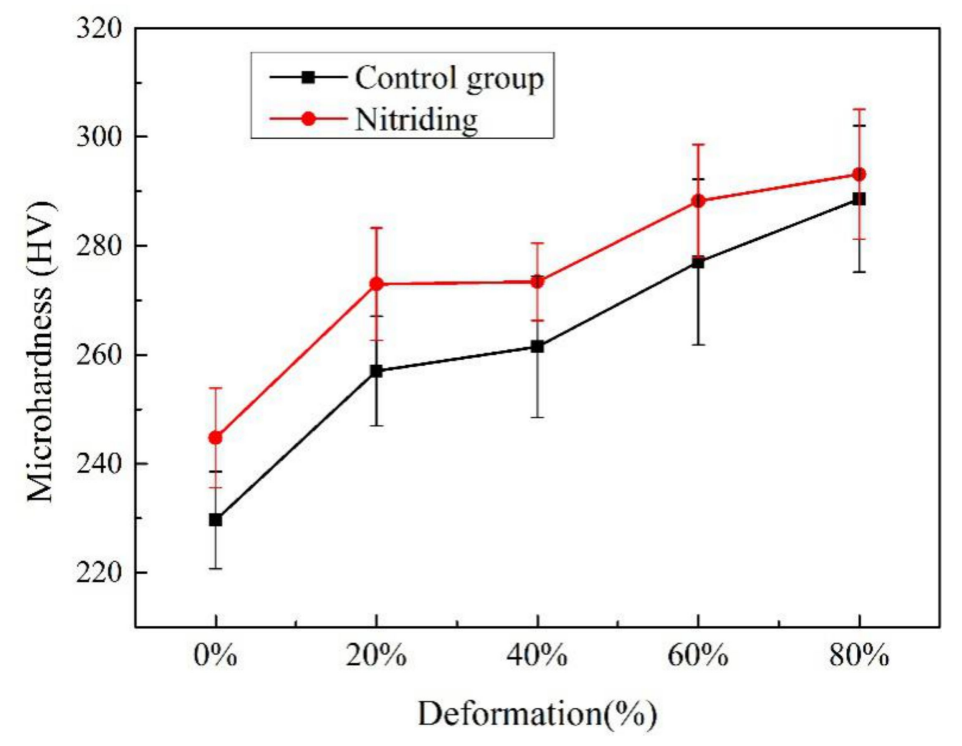

Figure 12. Microhardness values of cold-rolled deformed alloy samples before and after nitriding.

\section{Conclusions}

1. As the cold-rolling deformation rate of TA2 alloy increases, obvious grain refinement occurs, and the grain orientation changes from TD to RD and then to TD. The $\{11-20\}$ cylindrical texture component reduces, while the $\{0001\}$ basal surface texture and $\{10-10\}$ cone texture component increase, and the cone texture component is the largest.

2. It can be seen from the grain characteristics that the deformed sample undergoes recrystallization during low-temperature nitriding. The higher the degree of coldrolling deformation, the higher the degree of recrystallization, and the higher the degree of microstructure refinement. The comparison of texture characteristics before and after nitriding shows that the direction of $\{0001\}$ basal texture is deflected from TD to RD, and $\{10-10\}$ cylindrical texture components gradually increase; the c-axis of the TD-ND plane has $45-90^{\circ}$ deflection in the ND direction. As the degree of recrystallization increases, the texture orientation of the special angle gradually disappears.

3. After low-temperature plasma nitriding of the deformed alloy sample, the metastable nitriding phase TiN0.26 is formed on the surface. The surface N element content increases first and then decreases; this is because as the degree of deformation increases, the bonding force between atoms in the alloy matrix decreases and the defect density increases. Under different deformations, no obvious nitride layer is formed; this study may have formed a new type of nitrided zone. The composite process described in this article can significantly improve the wear resistance and hardness of deformed alloy samples.

4. In this paper, the cold-rolling deformation and low-temperature plasma nitriding caused simultaneous recrystallization and composite modification processes that we can use to effectively achieve the dual goals of alloy matrix structure control and surface modification and is of great significance for obtaining TA2 alloy materials with a strong plastic ratio. 
Author Contributions: Conceptualization, G.L. and H.S.; methodology, E.W.; software, K.S.; validation, X.Z. and Y.F.; formal analysis, G.L., H.S., and K.S.; investigation, K.S.; resources, Y.F. and X.Z.; data curation, E.W.; writing—original draft preparation, G.L.; writing-review and editing, G.L.; visualization, Y.F.; supervision, Y.F.; project administration, Y.F. All authors have read and agreed to the published version of the manuscript.

Funding: This research was funded by the Development of high-strength, high-toughness and largesize aluminum alloy plates for domestic large passenger aircraft, the type is Heilongjiang Province's "Hundreds, Millions" Engineering Science and Technology Major Project. This research was also funded by the Formation Mechanism and Control Technology of Functionalized Modified Coating on Titanium Alloy Surface, grant number 61429090307.

Institutional Review Board Statement: Not applicable.

Informed Consent Statement: Not applicable.

Data Availability Statement: Data is contained within the article.

Conflicts of Interest: Authors declare there are no conflict of interest.

\section{References}

1. Rack, H.J.; Qazi, J.I. Titanium alloys for biomedical applications. Mater. Sci. Eng. C 2006, 26, 1269-1277. [CrossRef]

2. Calvert, E.L.; Knowles, A.J.; Pope, J.J.; Dye, D.; Jackson, M. Novel high strength titanium-titanium composites produced using field-assisted sintering technology (FAST). Scr. Mater. 2019, 159, 51-57. [CrossRef]

3. Singh, P.; Pungotra, H.; Kalsi, N.S. On the characteristics of titanium alloys for the aircraft applications. Mater. Today Proc. 2017, 4, 8971-8982. [CrossRef]

4. Leyens, C.; Peters, M. (Eds.) Titanium and Titanium Alloys: Fundamentals and Applications; Wiley-VCH GmbH: Berlin, Germany, 2003.

5. Wang, X.; Qu, Z.; Li, J.; Zhang, E. Comparison study on the solution-based surface biomodification of titanium: Surface characteristics and cell biocompatibility. Surf. Coat. Technol. 2017, 329, 109-119. [CrossRef]

6. Lütjering, G.; Williams, J.C. Titanium Based Intermetallics; Springer: Berlin/Heidelberg, Germany, 2003.

7. Ruiliang, L.; Mufu, Y.; Yingjie, Q.; Yudong, F. Low temperature plasma RE nitrocarburizing of martensitic stainless steel. Heat Treat. Met. 2013, 38, 54-58.

8. Suwas, S.; Beausir, B.; Tóth, L.S.; Fundenberger, J.J.; Gottstein, G. Texture evolution in commercially pure titanium after warm equal channel angular extrusion. Acta Mater. 2011, 59, 1121-1133. [CrossRef]

9. Wang, Y.; He, W.; Liu, N.; Chapuis, A.; Luan, B.; Liu, Q. Effect of pre-annealing deformation on the recrystallized texture and grain boundary misorientation in commercial pure titanium. Mater. Charact. 2017, 136, 1-11. [CrossRef]

10. Gurao, N.P.; Sethuraman, S.; Suwas, S. Evolution of Texture and Microstructure in Commercially Pure Titanium with Change in Strain Path during Rolling. Metall. Mater. Trans. A 2013, 44, 1497-1507. [CrossRef]

11. Sahoo, S.K.; Sabat, R.K.; Sahni, S.; Suwas, S. Texture and microstructure evolution of commercially pure titanium during hot rolling: Role of strain-paths. Mater. Des. 2016, 91, 58-71. [CrossRef]

12. Bishoyi, B.D.; Sabat, R.K.; Sahoo, S.K. Effect of temperature on microstructure and texture evolutions during uniaxial compression of commercially pure titanium. Mater. Sci. Eng. A 2018, 718, 398-411. [CrossRef]

13. Rollett, A. Recrystallization and Related Annealing Phenomena; Elsevier: Amsterdam, The Netherlands, 1995.

14. Luo, Z.P.; Guo, X.K.; Hou, J.X.; Zhou, X.; Li, X.Y.; Lu, K. Plastic deformation induced hexagonal-close-packed nickel nano-grains. Scr. Mater. 2019, 168, 67-70. [CrossRef]

15. Zhang, X.Y.; Li, B.; Liu, Q. Non-equilibrium basal stacking faults in hexagonal close-packed metals. Acta Mater. 2015, 90, 140-150. [CrossRef]

16. Wang, Z.; Cochrane, C.; Skippon, T.; Dong, Q.; Daymond, M.R. Dislocation evolution at a crack-tip in a hexagonal close packed metal under plane-stress conditions. Acta Mater. 2018, 164, 25-38. [CrossRef]

17. Kaita, W.; Hagihara, K.; Rocha, L.A.; Nakano, T. Plastic deformation mechanisms of biomedical Co-Cr-Mo alloy single crystals with hexagonal close-packed structure. Scr. Mater. 2017, 142, 111-115. [CrossRef]

18. Contieri, R.J.; Zanotello, M.; Caram, R. Recrystallization and grain growth in highly cold worked CP-Titanium. Mater. Sci. Eng. A 2010, 527, 3994-4000. [CrossRef]

19. Hayama, A.O.; Andrade, P.N.; Cremasco, A.; Contieri, R.J.; Afonso, C.R.; Caram, R. Effects of composition and heat treatment on the mechanical behavior of Ti-Cu alloys. Mater. Des. 2014, 55, 1006-1013. [CrossRef]

20. Hayama, A.O.; Lopes, J.F.; Da Silva, M.J.; Abreu, H.F.; Caram, R. Crystallographic texture evolution in Ti-35Nb alloy deformed by cold rolling. Mater. Des. 2014, 60, 653-660. [CrossRef]

21. Kovacı, H.; Hacısalihoğlu, İ.; Yetim, A.F.; Çelik, A. Effects of shot peening pre-treatment and plasma nitriding parameters on the structural, mechanical and tribological properties of AISI 4140 low-alloy steel. Surf. Coat. Technol. 2019, 358, 256-265. [CrossRef] 
22. Kovacı, H.; Bozkurt, Y.B.; Yetim, A.F.; Aslan, M.; Çelik, A. The effect of surface plastic deformation produced by shot peening on corrosion behavior of a low-alloy steel. Surf. Coat. Technol. 2019, 360, 78-86. [CrossRef]

23. Xing'an, W.; Mufu, Y.; Ruiliang, L.; Zhang, Y. Effect of rare earth addition on microstructure and corrosion behavior of plasma nitrocarburized M50NiL steel. J. Rare Earths 2016, 11, 86-93.

24. Sun, H.Z.; Zheng, J.; Song, Y.; Chi, J.; Fu, Y.D. Effect of the deformation on nitrocarburizing microstructure of the cold deformed Ti-6Al-4V alloy. Surf. Coat. Technol. 2019, 362, 234-238. [CrossRef]

25. Zhu, X.S.; Fu, Y.D.; Li, Z.F.; Leng, K. Wear resistance of TC4 by deformation accelerated plasma nitriding at $400{ }^{\circ} \mathrm{C}$. J. Cent. South Univ. 2016, 23, 2771-2776. [CrossRef]

26. Fu, Y.D.; Zhu, X.S.; Li, Z.F.; Ke, L.E. Properties and microstructure of Ti6Al4V by deformation accelerated low temperature plasma nitriding. Trans. Nonferr. Met. Soc. China 2016, 26, 2609-2616. [CrossRef]

27. Kikuchi, S.; Ota, S.; Akebono, H.; Omiya, M.; Komotori, J.; Sugeta, A.; Nakai, Y. Formation of nitrided layer using atmosphericcontrolled IH-FPP and its effect on the fatigue properties of Ti-6Al-4V alloy under four-point bending. Procedia Struct. Integr. 2016, 2, 3432-3438. [CrossRef]

28. Tokaji, K.; Ogawa, T.; Shibata, H. The effects of gas nitriding on fatigue behavior in titanium and titanium alloys. J. Mater. Eng. Perform. 1999, 8, 159-167. [CrossRef]

29. Braz, J.K.; Martins, G.M.; Morales, N.; Naulin, P.; Fuentes, C.; Barrera, N.P.; Vitoriano, J.O.; Rocha, H.A.; Oliveira, M.F.; Alves, C., Jr.; et al. Live endothelial cells on plasma-nitrided and oxidized titanium: An approach for evaluating biocompatibility. Mater. Sci. Eng. C 2020, 113, 111014. [CrossRef] [PubMed]

30. Zeng, C.; Wen, H.; Ettefagh, A.H.; Zhang, B.; Gao, J.; Haghshenas, A.; Raush, J.R.; Guo, S.M. Laser nitriding of titanium surfaces for biomedical applications. Surf. Coat. Technol. 2020, 385, 125397. [CrossRef] 